\title{
Differential response of denitrifying community to the application of green manure and reduced chemical fertilizer in a paddy soil
}

\author{
Yu Fang ${ }^{1}$, Fei Wang ${ }^{1}$, Xianbo Jia ${ }^{1}$, Hui Zhang ${ }^{1}$, Chenqiang Lin ${ }^{1}$, Longjun Chen ${ }^{1}$, and Jichen Chen ${ }^{1^{*}}$ \\ 'Institute of Soil and Fertilizer, Fujian Academy of Agricultural Sciences, Fuzhou 350003, Fujian, P.R. China. \\ "Corresponding author (chenjichen2001@163.com).
}

Received: 7 January 2020; Accepted: 17 April 2020; doi:10.4067/S0718-58392020000300393

\begin{abstract}
Denitrification could lead to $\mathrm{N}$ loss from agricultural soil resulting in a low rate of $\mathrm{N}$ availability by crops. We investigated the response of nirK and nirS denitrifiers in a paddy soil to the incorporation of green manure and reduced chemical fertilizer. Soil samples were collected from plots of a short-term fertilization experiment initiated in 2009. The treatments were no chemical fertilizer, no Chinese milk vetch (Astragalus sinicus L., CK), chemical fertilizer (NPK), Chinese milk vetch (MV) plus 80\% chemical fertilizer (MF80), MV plus 60\% chemical fertilizer (MF60) and MV plus 40\% chemical fertilizer (MF40). Abundance and community composition of nirK and $n i r S$ denitrifiers were analyzed using quantitative PCR and Miseq sequencing. Reduced chemical fertilizer did not reduce content of total $\mathrm{N}$ and available $\mathrm{N}$ in soils amended with green manure. Abundances of $\operatorname{nir} K$ and $n i r S$ genes in different treatments were $1.04 \times 10^{8}$ to $4.89 \times 10^{8}$ and $1.22 \times 10^{7}$ to $7.04 \times 10^{7}$ copies $\mathrm{g}^{-1}$ soil, respectively, which were significantly higher in NPK treatment than those in soils with green manure. NirK abundance was positively correlated with the potential denitrifying activity (PDA) $\left(\mathrm{r}^{2}=0.827\right.$, $\mathrm{p}<0.01)$. Green manure combination with reduced chemical fertilizer significantly changed the community structure of nirK denitrifiers but not nirS denitrifiers relative to soils amended with chemical fertilizer and unfertilized soil. Shifts of community structure of nirK denitrifiers were closely associated with soil organic matter $\left(r^{2}=0.623, p=0.003\right)$, available $\mathrm{N}\left(\mathrm{r}^{2}=0.507, \mathrm{p}=0.01\right), \mathrm{pH}\left(\mathrm{r}^{2}=0.661, \mathrm{p}=0.006\right)$, and PDA $\left(\mathrm{r}^{2}=0.633, \mathrm{p}=0.005\right)$. In conclusion, nirK-type denitrifying community was more sensitive to the incorporation of green manure and reduced chemical fertilizer and they played a more important role in the denitrification process in this study.
\end{abstract}

Key words: Astragalus sinicus, green manure, $\operatorname{nir} K$, nirS, reduced chemical fertilizer.

\section{INTRODUCTION}

Denitrification is an important step in the environmental $\mathrm{N}$ cycle (Hayatsu et al., 2008), in which $\mathrm{NO}_{3}^{-}$and $\mathrm{NO}_{2}^{-}$are reduced to gaseous end products $\left(\mathrm{NO}, \mathrm{N}_{2} \mathrm{O}\right.$, and $\mathrm{N}_{2}$ ). Denitrification not only causes $\mathrm{N}$ losses from agricultural soil resulting in a low rate of $\mathrm{N}$ availability by crops but also contributes to greenhouse gas $\mathrm{N}_{2} \mathrm{O}$ emission (Chen et al., 2012). $\mathrm{N}_{2} \mathrm{O}$ has $310 \times$ the greenhouse gas warming capacity as $\mathrm{CO}_{2}$ (Lashof and Ahuja, 1990) and is also an important ozone-depleting substance (Ravishankara et al., 2009). Therefore, research on the denitrification is of economic and ecological importance.

Denitrification is catalyzed by nitrate reductase (NAR), nitrite reductase (NIR), nitric oxide reductase (NOR), and nitrous oxide reductase (NOS) (Zumft, 1997). NIR is thought to be the most important enzyme in the denitrification process because of its role in gas formation (Levy-Booth et al., 2014). NIR catalyzes the conversion of nitrite to nitric oxide and has been used as a molecular marker for denitrifying bacteria as only denitrifiers possess this enzyme (Braker et al., 2000). Two 
functionally-equivalent nitrite reductases are known: one contains copper ( $\mathrm{Cu}$-nir) and is encoded by the nirK gene, and the other contains cytochrome cd1 (cd1-nir) and is encoded by the nirS gene. These two genes are thought to be mutually exclusive among denitrifying species and to represent two ecologically distinct denitrifying groups (Jones and Hallin, 2010). Furthermore, the characterization of these nir genes can provide biological insights into total potential denitrification (Morales et al., 2010).

Chemical fertilizers have been used to improve soil fertility and increase crop productivity. To meet the needs of intensive agriculture, heavy inputs of chemical fertilizers have been applied to soil (Savci, 2012). However, excess application of mineral $\mathrm{N}$ has resulted in serious and long-term environmental consequences (Canfield et al., 2010). An alternative to conventional farming is to amend soils with organic $\mathrm{N}$ fertilizer which allows the recycling of already-fixed $\mathrm{N}$ (Vitousek et al., 1997). Chinese milk vetch (Astragalus sinicus L., MV) is considered the most popular green manure in the paddy fields of South China due to its high potential to fix N. Green manure can reduce chemical fertilizer application rates (Macguidwin et al., 2012). Reduced $\mathrm{N}$ fertilizer helps to reduce $\mathrm{N}$ loss from agricultural soils. Fertilization practices have been considered as an important driver of soil microbial succession (Cruz et al., 2009). Previous studies have demonstrated that the abundance and community structures of $n i r K$ and $n i r S$ denitrifiers respond differently to fertilization regimes (Yin et al., 2015; Cui et al., 2016). Chen et al. (2010) also revealed that the community composition of denitrifiers possessing nirK in a paddy soil were more sensitive to the fertilization practices than those with nirS, however, fertilization regimes had similar impact on the abundances of $\operatorname{nir} K$ and $\operatorname{nir} S$ genes. Moreover, the response of abundances of $\operatorname{nir} K$ and nir $S$ genes to different $\mathrm{N}$ fertilization rates were different. The abundances of $\operatorname{nir} K$ gene increased with $\mathrm{N}$ fertilization increments while significantly low numbers of nirS gene were observed in the treatments with more $\mathrm{N}$ fertilization in an alkaline northern Chinese soil (Yang et al., 2017). Although the effects of fertilization regimes on the nir genes have been investigated, most studies have focused on chemical and organic fertilization. Little is known about the effect of green manure combination with reduced chemical fertilizer on the abundance and community structure of the denitrifiers in a paddy field.

China is one of the major rice producers, accounting for $28 \%$ of all paddy fields globally (FAO, 2003). Denitrification is a major $\mathrm{N}$ transformation process in paddy soils due to the anaerobic condition in soil resulting in considerable amounts of $\mathrm{N}_{2} \mathrm{O}$ emissions (Yan et al., 2000). Therefore, the main objectives of this study were to determine the effects of green manure and reduced chemical fertilizer on the abundance, diversity, and composition of denitrifiers with nirK and nirS genes and to explore the responses of denitrifiers to green manure with reduced chemical fertilizer in a paddy soil in South China.

\section{MATERIALS AND METHODS}

\section{Field description and soil sampling}

The study area was at the Baisha Experimental Station (119 $04^{\prime} 10^{\prime \prime}$ E, $\left.26^{\circ} 13^{\prime} 31^{\prime \prime} \mathrm{N}\right)$, which is located in the Minhou County, Fuzhou, Fujian Province, China. The area has a subtropical monsoonal climate, the average annual temperature is $19.5^{\circ} \mathrm{C}$ with an average annual precipitation of $1350 \mathrm{~mm}$. The soil is classified as typic Hapli-Stagnic Anthrosols (USDA). A short-term (i.e., $8 \mathrm{yr}$ ) fertilization experiment was initiated in 2009, including five treatments with three replicates for each treatment in a random plot design. Each plot was $15 \mathrm{~m}^{2}$. The treatments were control (CK, no chemical fertilizer, no green manure), chemical fertilizer alone (NPK), Chinese milk vetch (Astragalus sinicus L., MV) plus $80 \%$ chemical fertilizer (MF80), MV plus 60\% chemical fertilizer (MF60), MV plus 40\% chemical fertilizer (MF40). Chemical fertilizer (urea, $81 \mathrm{~kg} \mathrm{~N}$ ha $^{-1}$; superphosphate, $54 \mathrm{~kg} \mathrm{P}_{2} \mathrm{O}_{5}$ ha $^{-1}$; potassium chloride, $56.7 \mathrm{~kg} \mathrm{~K}_{2} \mathrm{O}$ ha $^{-1}$ ) was used as base fertilizer and $\mathrm{N}\left(54 \mathrm{~kg} \mathrm{ha}^{-1}\right)$ and $\mathrm{K}_{2} \mathrm{O}\left(37.8 \mathrm{~kg} \mathrm{ha}^{-1}\right)$ were used in the tillering stage. The rotation of rice (Oryza sativa $\mathrm{L}$.) and MV was employed, and the rice season was from July to October. Each MV treatment received the same concentration of MV (18000 kg ha-1 from 2009 to 2014; $22500 \mathrm{~kg} \mathrm{ha}^{-1}$ after 2014) which contained $101 \mathrm{~g} \mathrm{~kg}^{-1}$ organic matter, 3.7, 1.1, and 2.8 $\mathrm{g} \mathrm{kg}^{-1} \mathrm{~N}, \mathrm{P}$, and $\mathrm{K}$, respectively, and $86.2 \%$ water. Chinese milk vetch was sown in November and returned to the soils in April of next year. The soil sample was collected from the surface $(0-20 \mathrm{~cm}$ in depth) of a paddy soil in October 2016 (after the rice harvest). The soil moisture in the different treatments was $33.16 \%-34.42 \%$. The samples were separated into two subsamples: the first sub-sample was stored at $4{ }^{\circ} \mathrm{C}$ for chemical analysis and potential denitrifying activity while the second sub-sample was stored at $-80{ }^{\circ} \mathrm{C}$ for molecular analyses. 


\section{Soil chemical properties}

Soil organic matter was measured by the $\mathrm{K}_{2} \mathrm{Cr}_{2} \mathrm{O}_{7}$ oxidation method, total $\mathrm{N}$ with the Kjeldahl digestion analysis, available $\mathrm{N}$ with the $\mathrm{NaOH}$ hydrolyzable method (Lu, 2000). Soil ammonium $\mathrm{N}$ was determined by extracting the soil with $2 \mathrm{M} \mathrm{KCl}$ solution and then detected by indophenol blue colorimetric method. The nitrate $\mathrm{N}$ was determined by dual wavelength spectrophotometry method (Huang et al., 2009). Soil pH was measured by a pH meter using a soil-to-water ratio of 1:2.5 (Alfaro et al., 2018). Potential denitrifying activity (PDA) was evaluated according to the acetylene inhibition method (Pell et al., 1996). Briefly, $10 \mathrm{~g}$ fresh soil were placed in $100 \mathrm{~mL}$ flasks containing $10 \mathrm{~mL}$ substrate with $1 \mathrm{mM}$ glucose and $1 \mathrm{mM} \mathrm{KNO}_{3}$. Denitrifying conditions were achieved by flushing the headspace with pure $\mathrm{N}$ gas (99.9\%) three times. Ten milliliters of acetylene were injected to inhibit the $\mathrm{N}_{2} \mathrm{O}$ reductase. Soils were incubated on a rotary shaker at $25^{\circ} \mathrm{C}$ for $6 \mathrm{~h}$. Head space samples were collected every $2 \mathrm{~h}$. Nitrous oxide was measured with a gas chromatograph (7890A, Agilent, Santa Clara, California, USA).

\section{Soil DNA extraction}

Total DNA was extracted from $0.25 \mathrm{~g}$ (fresh weight) of each soil sample using a soil DNA isolation kit (UltraClean, MO BIO Laboratories, San Diego, California, USA) according to the manufacturer's instruction. The concentration of extracted DNA was quantified by NanoDrop 2000 UV-vis spectrophotometer (Thermo Scientific, Waltham, Massachusetts, USA).

\section{Quantitative real-time PCR for nirK and nirS genes}

Primer sets 583F/909R for nirK (Yan et al., 2003) and cd3aF/R3cd for nirS (Throbäck et al., 2004) were used to measure the abundances of denitrifiers using a 7500 Real-Time PCR System (Applied Biosystems, Foster City, California, USA). The 20- $\mu \mathrm{L}$ qPCR reaction mixture contained 16.4 $\mu \mathrm{L}$ SYBRGreen qPCR Master Mix (Takara Bio, Dalian, Liaoning, China), $0.8 \mu \mathrm{L}$ forward and reverse primer $(10 \mu \mathrm{M})$ and $2 \mu \mathrm{L}$ DNA template. Quantitative real-time PCR parameters were: hold at $95^{\circ} \mathrm{C}$ for $10 \mathrm{~min}$, then 40 cycles of $15 \mathrm{~s}$ at $95^{\circ} \mathrm{C}$, and $1 \mathrm{~min}$ at $55^{\circ} \mathrm{C}$ for $\operatorname{nirK}$ and $56^{\circ} \mathrm{C}$ for $\operatorname{nir} S$, respectively. Both nirK and nirS gene fragments were cloned in pMD-19 plasmid and the right gene inserts were chosen. Standard curves were obtained by serially diluting plasmid. The amplification efficiency was $94.25 \%\left(\mathrm{r}^{2}=0.9999\right)$ for $n$ ir $K$ and $90.86 \%$ $\left(r^{2}=0.9943\right)$ for nir $S$, respectively.

\section{High-throughput sequencing of the nirK and nirS genes for denitrifying bacteria}

Primer sets of 1aCuF/R3CuR for nirK (Hallin and Lindgren, 1999) and cd3aF/R3cd for nirS (Throbäck et al., 2004) were selected to amplify the gene fragment by thermocycler PCR system (9700 GeneAmp, Applied Biosystems). The PCR reactions for nirK and nirS were conducted using the following program: 3 min denaturation at $95{ }^{\circ} \mathrm{C}, 35$ cycles of $30 \mathrm{~s}$ at $95{ }^{\circ} \mathrm{C}, 30 \mathrm{~s}$ for annealing at $55^{\circ} \mathrm{C}$, and $45 \mathrm{~s}$ for elongation at $72{ }^{\circ} \mathrm{C}$, and a final extension at $72{ }^{\circ} \mathrm{C}$ for $10 \mathrm{~min}$. PCR reactions were performed in triplicate in total volume of $20 \mu \mathrm{L}$ PCR mixture containing $5 \times$ FastPfu buffer $(4 \mu \mathrm{L})$, $2.5 \mathrm{mM}$ dNTPs $(2 \mu \mathrm{L}), 5 \mu \mathrm{M}$ each primer $(0.8 \mu \mathrm{L})$, FastPfu Polymerase $(0.4 \mu \mathrm{L}), 0.2 \mu \mathrm{L}$ of BSA and $10 \mathrm{ng}$ template DNA. The resulted PCR products were extracted from a $2 \%$ agarose gel and further purified using the AxyPrep DNA Gel Extraction Kit (Axygen Biosciences, Union City, California, USA) and quantified using single-tube fluorometer (QuantiFluor-ST, Promega, Madison, Wisconsin, USA) according to the manufacturer's protocol. Purified amplicons were pooled in equimolar and paired-end sequenced $(2 \times 300)$ on an Illumina MiSeq platform (Illumina, San Diego, California, USA) according to the standard protocols by Majorbio Bio-Pharm Technology Co. Ltd. (Shanghai, China). The raw reads of nirK and nirS were deposited into the NCBI Sequence Read Archive (SRA) database (accession number: PRJNA544986 and PRJNA545044).

\section{Sequence data analysis}

Raw fastq files were demultiplexed, quality-filtered by Trimmomatic and merged by FLASH with the following criteria: (i) Reads were truncated at any site receiving an average quality score $<20$ over a 50 bp sliding window. (ii) Primers were exactly matched allowing 2 nucleotide mismatching, and reads containing ambiguous bases were removed. (iii) Sequences whose overlap longer than $10 \mathrm{bp}$ were merged according to their overlap sequence. Operational taxonomic units (OTUs) were clustered with 97\% similarity cutoff using UPARSE (version $7.1 \mathrm{http} / / /$ drive5.com/uparse/) and chimeric sequences were identified and removed using UCHIME. The taxonomy of each nirK and $\operatorname{nir} S$ gene sequence was determined using 
the Ribosomal Database Project (RDP) database (http://rdp.cme.msu.edu/). Principal coordinate analysis (PCoA) and redundancy analysis (RDA) were performed using R software version 3.2.1 (R Foundation for Statistical Computing, Vienna, Austria).

\section{Statistical analysis}

Treatment effects were determined using one-way ANOVA with SPSS 19.0 (IBM Software, Armonk, New York, USA). Comparison of means was compared using Duncan's test at a significant level of $\mathrm{p}<0.05$. Pearson correlation analysis was used to determine the correlation between the denitrifiers abundances and soil properties. Figures were plotted using GraphPad Prism 5.0 (GraphPad Software, San Diego, California, USA).

\section{RESULTS}

\section{Soil properties and PDA under different fertilization regimes}

The effects of green manure and reduced chemical fertilizer on soil properties are presented in Table 1. Compared with NPK treatment, fertilization treatments with MV caused an increase in the organic matter $(\mathrm{p}<0.05)$. Fertilization treatments with MV increased the concentration of total $\mathrm{N}$ in contrast to the $\mathrm{CK}$, but there was nonsignificant difference between treatments with MV and NPK treatment, and between NPK treatment and the CK. Compared with the CK, AN content in the fertilized treatments had a significant increase $(\mathrm{p}<0.05)$. Moreover, fertilizer reduction did not decrease the content of AN and even MF60 had the highest AN content. Fertilization decreased the concentration of $\mathrm{NH}_{4}{ }^{+} \mathrm{N}$ and MF40 treatment had the lowest $\mathrm{NH}_{4}{ }^{+}-\mathrm{N}$ content. The concentration of $\mathrm{NO}_{3}^{-}-\mathrm{N}$ in the MF60 and MF40 treatments were significantly lower than that in the NPK treatment $(\mathrm{p}<0.05)$ and there was nonsignificant difference in the $\mathrm{NO}_{3}^{-}-\mathrm{N}$ concentration between MF80 and NPK treatment. The $\mathrm{pH}$ values among the different treatments varied between 5.23 and 5.53. Application of fertilizer significantly decreased the $\mathrm{pH}$ compared with $\mathrm{CK}$ and there were no distinct differences among the fertilized soils. Different fertilization regimes had a significant impact on the potential denitrifying activity (PDA). PDA was significantly higher in the fertilized treatments than that in CK $(\mathrm{p}<0.05)$. The highest PDA was observed in the plot amended with chemical fertilizer (NPK treatment). The plots with the green manure combination with reduced chemical fertilizer decreased soil PDA. Moreover, PDA in MF80 treatment was significantly higher than those in MF60 and MF40 treatments ( $<$ 0.05).

\section{Abundances of nirK and nirS denitrifiers under different fertilization regimes}

The abundance of nirK denitrifiers were significantly greater in soils under NPK compared to CK, however nonsignificant difference in the abundance of nirS denitrifiers between NPK and CK were observed (Figures 1a and 1b). Green manure combination with reduced chemical fertilizer decreased the abundances of nirK and nirS denitrifiers in comparison with NPK treatment. However, the abundances of $\operatorname{nir} K$ and $\operatorname{nir} S$ denitrifiers responded differently towards the fertilization regimes. There were nonsignificant differences in nirK abundances among green manure treatments, however, there were significant variations in the copy number of nirS gene among the green manures. The quantity of nirS gene in MF80, MF60 and MF40 treatments were $64.36 \%, 82.76 \%$ and $27.80 \%$ less than that in NPK treatment, respectively. Correlation analysis showed that nirS abundance was strongly negatively correlated with soil OM, TN and AN, but

Table 1. Soil properties and potential denitrifying activity (PDA) under different fertilization regimes.

\begin{tabular}{|c|c|c|c|c|c|c|c|}
\hline Treatment & $\mathrm{OM}$ & $\mathrm{TN}$ & AN & $\mathrm{NH}_{4}{ }^{+}-\mathrm{N}$ & $\mathrm{NO}_{3}^{-}-\mathrm{N}$ & $\mathrm{pH}$ & PDA \\
\hline & \multicolumn{2}{|c|}{$\longrightarrow \mathrm{g} \mathrm{kg}^{-1}$} & $\longrightarrow$ & $\mathrm{mg} \mathrm{kg}^{-1}$ & & & ng N $\mathrm{N}_{2} \mathrm{O}-\mathrm{N} \mathrm{g}^{-1}$ dry soil h${ }^{-1}$ \\
\hline CK & $20.13 \pm 0.70 b$ & $1.20 \pm 0.04 b$ & $97.40 \pm 1.83 \mathrm{c}$ & $5.28 \pm 1.34 \mathrm{a}$ & $4.43 \pm 0.22 \mathrm{a}$ & $5.53 \pm 0.12 \mathrm{a}$ & $25.69 \pm 1.03 \mathrm{~d}$ \\
\hline NPK & $20.87 \pm 0.25 b$ & $1.25 \pm 0.05 \mathrm{ab}$ & $102.67 \pm 0.57 b$ & $3.45 \pm 0.63 b c$ & $4.53 \pm 0.19 \mathrm{a}$ & $5.40 \pm 0.10 b$ & $61.24 \pm 0.88 \mathrm{a}$ \\
\hline MF80 & $23.23 \pm 1.01 \mathrm{a}$ & $1.27 \pm 0.04 \mathrm{a}$ & $102.80 \pm 2.75 b$ & $3.98 \pm 0.25 b$ & $5.06 \pm 0.97 \mathrm{a}$ & $5.27 \pm 0.06 b$ & $47.41 \pm 1.14 \mathrm{~b}$ \\
\hline MF60 & $22.70 \pm 0.56 a$ & $1.30 \pm 0.02 \mathrm{a}$ & $109.03 \pm 3.07 \mathrm{a}$ & $2.62 \pm 0.41 \mathrm{~cd}$ & $3.28 \pm 0.61 b$ & $5.23 \pm 0.12 b$ & $45.37 \pm 1.09 \mathrm{c}$ \\
\hline MF40 & $23.10 \pm 0.69 \mathrm{a}$ & $1.29 \pm 0.01 \mathrm{a}$ & $107.43 \pm 2.57 \mathrm{a}$ & $2.06 \pm 0.54 \mathrm{~d}$ & $3.63 \pm 0.27 b$ & $5.27 \pm 0.06 b$ & $44.59 \pm 1.04 \mathrm{c}$ \\
\hline
\end{tabular}

CK: No chemical fertilizer and green manure; NPK: chemical fertilizer alone; MF80: Chinese milk vetch plus 80\% chemical fertilizer; MF60: Chinese milk vetch plus $60 \%$ chemical fertilizer; MF40: Chinese milk vetch plus $40 \%$ chemical fertilizer; OM: organic matter; TN: total N; AN: available N.

Different letters in the row indicate significant differences according to Duncan's test $(\mathrm{p}<0.05)$. 
Figure 1. Copy number of nirK (a) and $\operatorname{nir} S$ (b) genes across different fertilization regimes.
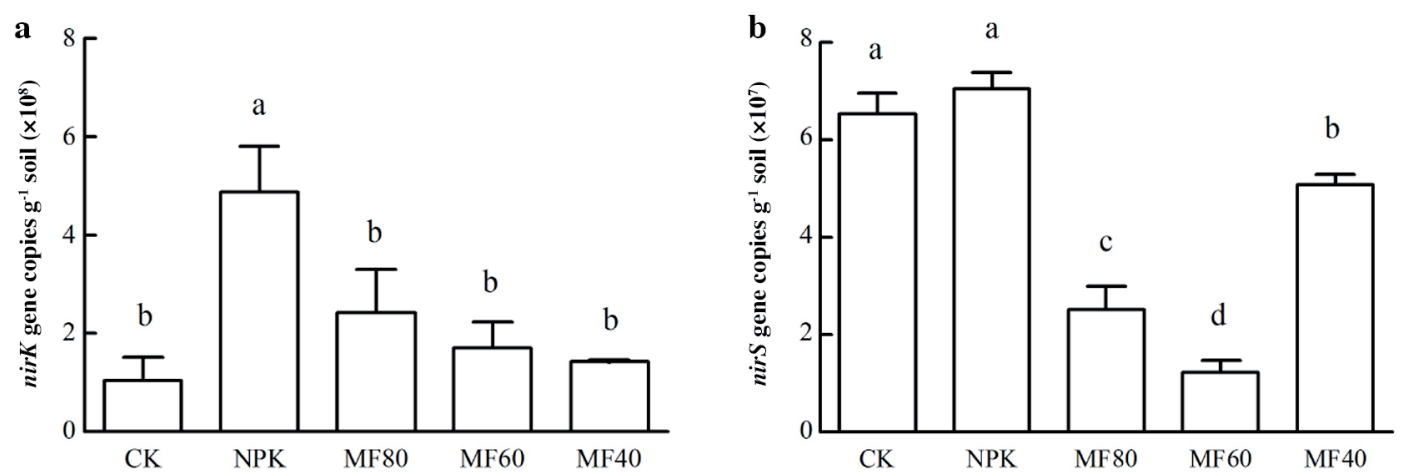

CK: No chemical fertilizer and green manure; NPK: chemical fertilizer alone; MF80: Chinese milk vetch plus 80\% chemical fertilizer; MF60: Chinese milk vetch plus $60 \%$ chemical fertilizer; MF40: Chinese milk vetch plus $40 \%$ chemical fertilizer.

Different letters on bars indicate significant differences between treatments according to Duncan test $(\mathrm{p}<0.05)$.

positively correlated with soil $\mathrm{pH}$ (Table 2). However, no such correlations existed between $\operatorname{nirK}$ abundance and soil properties. Furthermore, PDA was significantly positively correlated with the copy number of $\operatorname{nirK}\left(\mathrm{r}^{2}=0.827, \mathrm{p}<0.01\right.$ by Pearson correlation test).

\section{Richness and diversity of the denitrifiers under different fertilization regimes}

After removing low-quality sequences, a total of $227571 \mathrm{nirK}$ sequences and $214345 \mathrm{nirS}$ sequences were obtained in the five treatments (a total of 15 soil samples). The sequences were assigned to 306-480 OTUs for nirK and 233-291 OTUs for nirS at the $97 \%$ similarity level, respectively. The OTU number of nirK gene was significantly higher than that of nirS gene in each treatment. Incorporation of green manure and reduced chemical fertilizer had little impact on the richness of denitrifier-related OTUs (estimated by Chao1) (Table 3). There was a significant difference in the Chao 1 index of nirK between MF40 and other treatments, and that of nirS between MF60 and other treatments. Application of chemical fertilizer alone (NPK) significantly decreased the Shannon index of nirK and nirS gene compared with that of the CK. When compared with NPK treatment, green manure plus reduced chemical fertilizer significantly decreased the Shannon index of nirK gene by $10.8 \%$ in MF80, and $16.9 \%$ in MF40. In contrast, the Shannon index of nirS gene in the green manure treatments significantly increased by $7.9 \%, 13.9 \%$ and $9.0 \%$, compared with NPK treatment, respectively.

Table 2. Correlation between the abundance of nirK and nirS denitrifiers and soil properties.

\begin{tabular}{lccccccc}
\hline & $\mathrm{OM}$ & $\mathrm{TN}$ & $\mathrm{AN}$ & $\mathrm{NH}_{4}{ }^{+}-\mathrm{N}$ & $\mathrm{NO}_{3}-\mathrm{N}$ & $\mathrm{pH}$ & $\mathrm{PDA}$ \\
\hline nirK & -0.134 & 0.099 & -0.038 & -0.042 & 0.371 & -0.105 & $0.827 * *$ \\
nir $S$ & $-0.681^{*}$ & $-0.538^{*}$ & $-0.549^{*}$ & 0.302 & 0.291 & $0.580^{*}$ & -0.033 \\
\hline
\end{tabular}

OM: Organic matter; TN: total N; AN: available N; PDA: potential denitrifying activity.

$*, * *$ Indicate that abundance of denitrifiers is significantly correlated with soil properties at $\mathrm{p}<0.05$ and $\mathrm{p}<0.01$, respectively.

Table 3. Richness and diversity of nirK and nirS denitrifiers under different fertilization regime.

\begin{tabular}{|c|c|c|c|c|c|c|c|c|}
\hline \multirow[b]{2}{*}{ Treatment } & \multicolumn{4}{|c|}{$\operatorname{nir} K$} & \multicolumn{4}{|c|}{$\operatorname{nir} S$} \\
\hline & OTUs & Shannon & Chao1 & Coverage (\%) & OTUs & Shannon & Chao1 & Coverage $(\%)$ \\
\hline CK & $480 \pm 29 a$ & $4.54 \pm 0.02 \mathrm{a}$ & $695 \pm 10 a$ & $97.88 \pm 0.42 \mathrm{a}$ & $259 \pm 80 a b$ & $4.01 \pm 0.14 \mathrm{a}$ & $334 \pm 18 b$ & $99.03 \pm 0.05 a$ \\
\hline NPK & $480 \pm 57 a$ & $4.27 \pm 0.05 b$ & $746 \pm 34 a$ & $97.90 \pm 0.27 \mathrm{a}$ & $240 \pm 10 b$ & $3.68 \pm 0.07 b$ & $327 \pm 31 b$ & $98.98 \pm 0.14 \mathrm{a}$ \\
\hline MF80 & $438 \pm 28 \mathrm{a}$ & $3.81 \pm 0.13 c$ & $609 \pm 24 a b$ & $98.05 \pm 0.05 a$ & $233 \pm 40 b$ & $3.97 \pm 0.02 \mathrm{a}$ & $332 \pm 00 b$ & $99.05 \pm 0.09 a$ \\
\hline MF60 & $453 \pm 52 \mathrm{a}$ & $4.11 \pm 0.02 b$ & $656 \pm 77 a$ & $98.06 \pm 0.17 \mathrm{a}$ & $291 \pm 26 a$ & $4.19 \pm 0.01 \mathrm{a}$ & $389 \pm 40 \mathrm{a}$ & $98.95 \pm 0.06 \mathrm{a}$ \\
\hline MF40 & $306 \pm 21 b$ & $3.55 \pm 0.03 d$ & $468 \pm 70 b$ & $98.61 \pm 0.32 \mathrm{a}$ & $243 \pm 10 b$ & $4.01 \pm 0.10 \mathrm{a}$ & $312 \pm 23 b$ & $99.11 \pm 0.03 a$ \\
\hline
\end{tabular}

CK: No chemical fertilizer and green manure; NPK: chemical fertilizer alone; MF80: Chinese milk vetch plus $80 \%$ chemical fertilizer; MF60: Chinese milk vetch plus $60 \%$ chemical fertilizer; MF40: Chinese milk vetch plus $40 \%$ chemical fertilizer; OTUs: operational taxonomic units. Different letters in the row indicate significant differences according to Duncan's test $(\mathrm{p}<0.05)$. 


\section{Community structure of the denitrifiers under different fertilization regimes}

Proteobacteria accounted for the largest proportion of the nirK denitrifier (57.7\%-78.4\%, data not shown). At the order level, most nirK denitrifiers were assigned to Rhizobiales (33\%-54.7\%) (Figure 2a). Combined application of green

Figure 2. Compositional structures of nirK and nirS denitrifiers at order (a and c) and genus (b and d) level across different fertilization regimes.
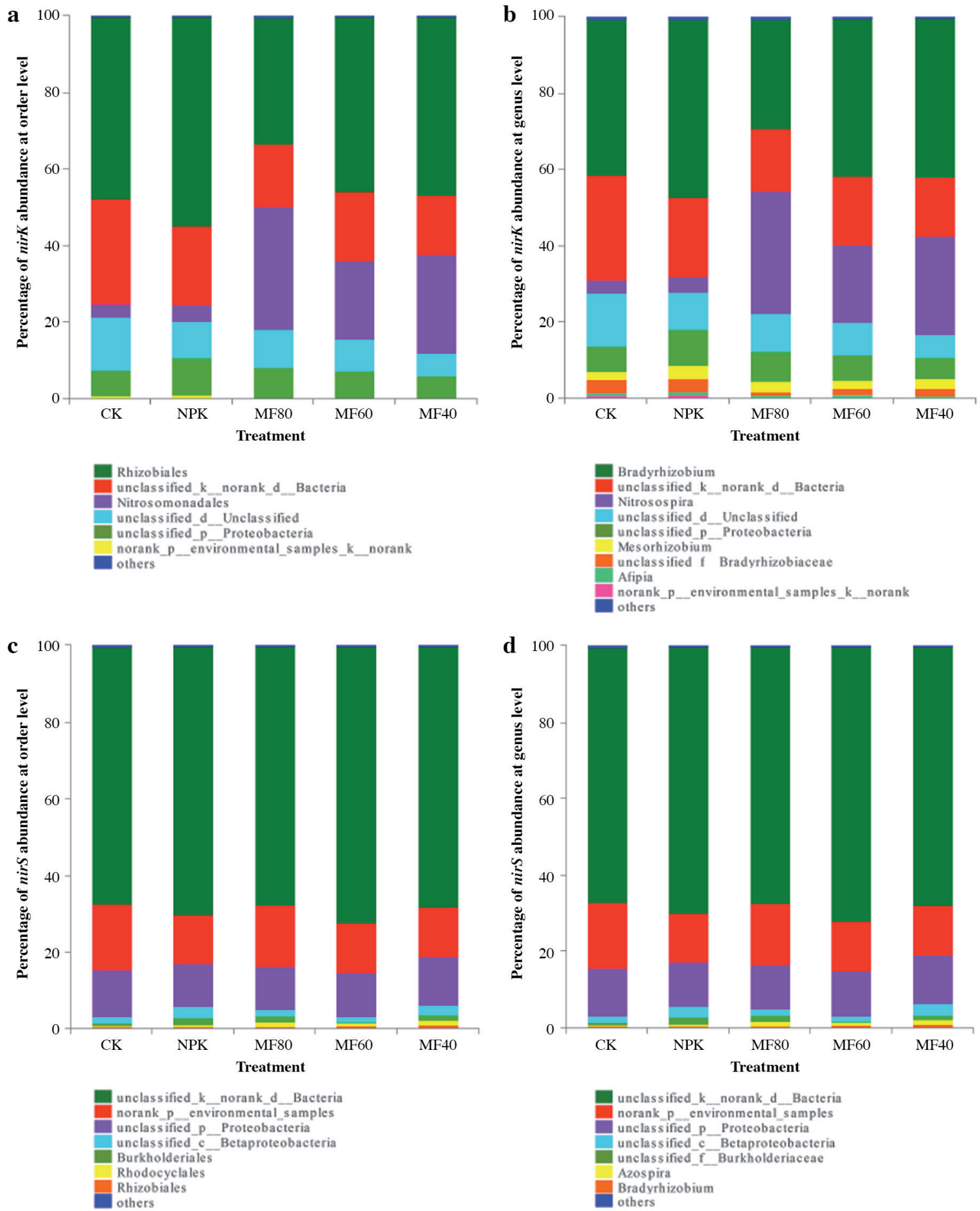

CK: No chemical fertilizer and green manure; NPK: chemical fertilizer alone; MF80: Chinese milk vetch plus 80\% chemical fertilizer; MF60: Chinese milk vetch plus $60 \%$ chemical fertilizer; MF40: Chinese milk vetch plus $40 \%$ chemical fertilizer. 
manure and reduced chemical fertilizer decreased the relative abundance of Rhizobiales compared with NPK treatment. Nitrosomonadales was another dominant order of nirK community. The abundance of Nitrosomonadales was significantly higher in the green manure treatments $(20.4 \%-32.1 \%)$ than in CK and NPK treatment $(<5 \%)$. The dominant genera of nirK denitrifiers were Bradyrhizobium (28.8\%-46.7\%), Nitrosospira (3.4\%-32.1\%), and Mesorhizobium (2.0\%-3.4\%) (Figure 2b). Other genera included unclassified Proteobacteria (5.61\%-9.53\%) and unclassified Bradyrhizobiaceae (1.62\%-3.58\%). Compared with NPK treatment, combined application of green manure and reduced chemical fertilizer significantly increased the relative abundance of the genus Nitrosospira $(\mathrm{p}<0.05)$ but decreased the abundance of unclassified Bradyrhizobiaceae ( $<$ 0.05). For nirS denitrifiers, the dominant phylum was also Proteobacteria with the relative abundance of $15.01 \%-19.26 \%$ (data not shown). At the order level, most nirS denitrifiers were assigned to unclassified bacteria, and identified dominant nirS denitrifiers were Burkholderiales, Rhodocyclales and Rhizobiales (Figure 2c). At the genus level, most nirS denitrifiers were belonged to unclassified bacteria (66.95\%-71.97\%). The identified dominant nirS denitrifiers were Azospira and Bradyrhizobium. Unclassified Proteobacteria, unclassified Betaproteobacteria and unclassified Burkholderiaceae were also the dominant nirS denitrifier (Figure 2d). There were nonsignificant differences in the relative abundance of each genus among different fertilization regimes.

The PCoA analysis was performed to determine the variations in the community structures of nirK and nirS denitrifiers among different fertilization managements (Figure 3). Axis 1 and axis 2 explained $78.90 \%$ of the variation of nirK community. Green manure treatments (i.e. MF80, MF60 and MF40) were grouped together, while NPK and CK treatments

Figure 3. Principal coordinate analysis of community structures of nirK (a) and nirS (b) denitrifiers at the genus level.
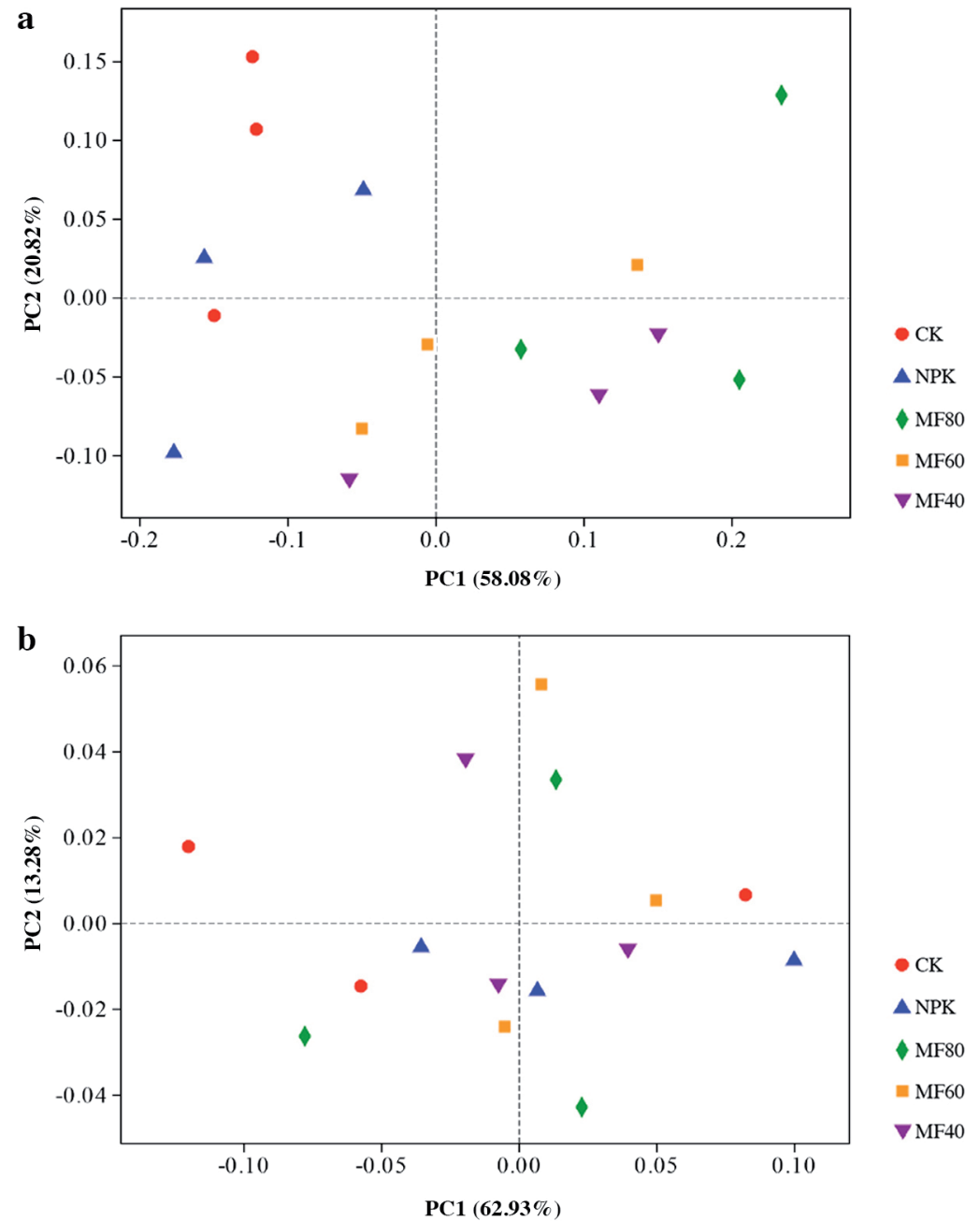

CK: No chemical fertilizer and green manure; NPK: chemical fertilizer alone; MF80: Chinese milk vetch plus 80\% chemical fertilizer; MF60: Chinese milk vetch plus $60 \%$ chemical fertilizer; MF40: Chinese milk vetch plus $40 \%$ chemical fertilizer. 
were grouped together (Figure 3a). These indicated that the incorporation of green manure had a strong effect on the variation in $\operatorname{nirK}$ community while the application rates of chemical fertilizer had little effect on nirK community. In contrast, nirS denitrifier community in all treatments were scattered, suggesting that both green manure and chemical fertilizer exert weak effect on the community structure of nirS denitrifier (Figure 3b).

\section{Environmental effect on the community structures of denitrifiers}

Redundancy analysis (RDA) was used to determine the relationship between denitrifying community and the soil properties. The first two RDA axes together explained $54.51 \%$ of the total variation in the composition of nirK denitrifiers (Figure 4a). Soil OM $\left(\mathrm{r}^{2}=0.623, \mathrm{p}=0.003\right), \mathrm{AN}\left(\mathrm{r}^{2}=0.507, \mathrm{p}=0.01\right), \mathrm{pH}\left(\mathrm{r}^{2}=0.661, \mathrm{p}=0.006\right)$ and PDA $\left(\mathrm{r}^{2}=0.633, \mathrm{p}\right.$ $=0.005$ ) significantly affected the community structure of nirK denitrifiers. Similarly, axis 1 and axis 2 explained 39.02\% of the total variation in nirS composition (Figure 4b), but all soil factors had no significant effects on the community structure of nirS denitrifiers.

Figure 4. Redundancy analysis (RDA) of community structures of nirK (a) and nirS denitrifiers and soil variables.
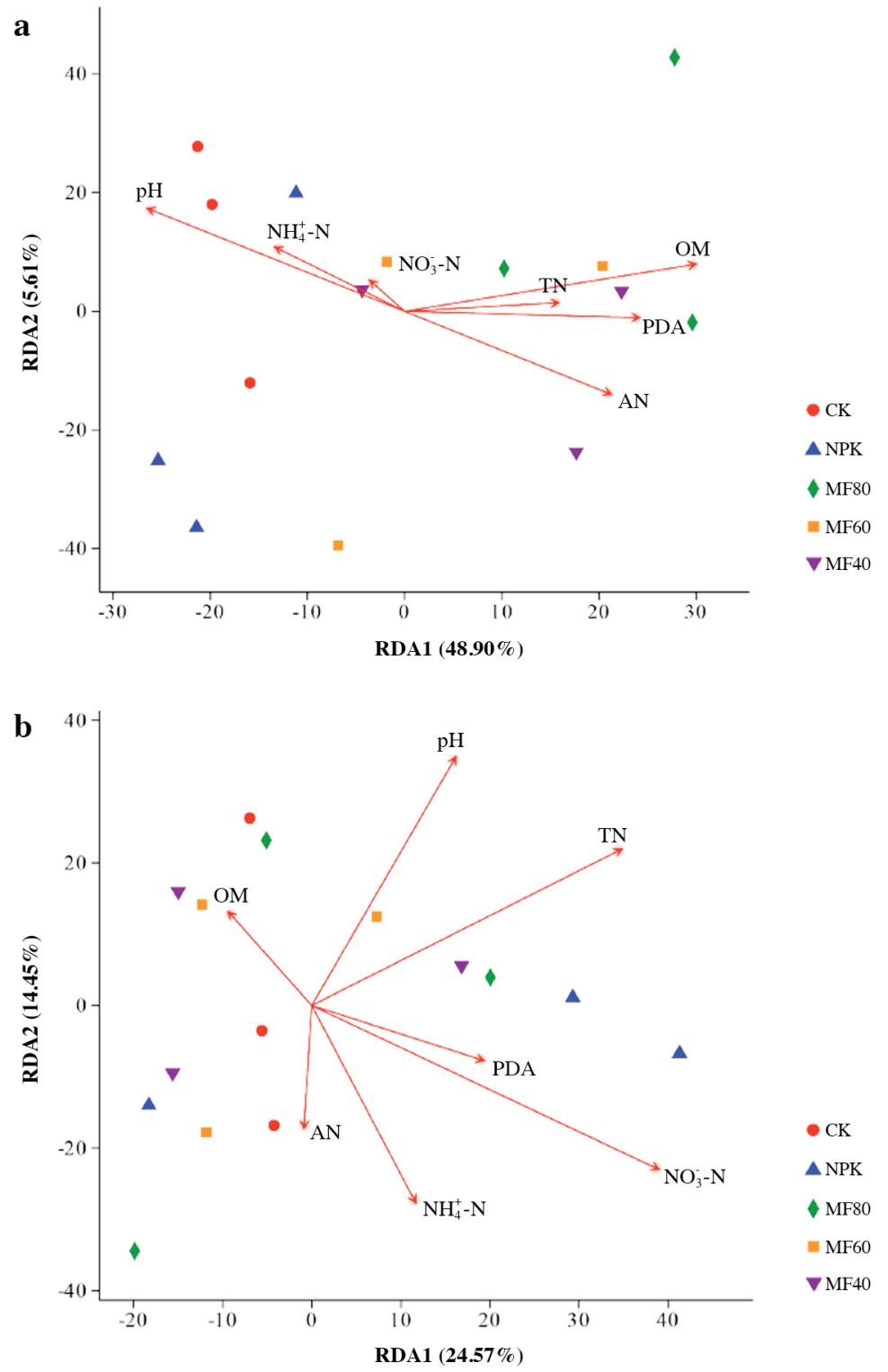

CK: No chemical fertilizer and green manure; NPK: chemical fertilizer alone; MF80: Chinese milk vetch plus 80\% chemical fertilizer; MF60: Chinese milk vetch plus $60 \%$ chemical fertilizer; MF40: Chinese milk vetch plus $40 \%$ chemical fertilizer. 


\section{DISCUSSION}

Fertilization regimes exhibited various effects on the population sizes of the denitrifiers in this study. In general, the abundances of nirK and nirS denitrifiers in soils with chemical fertilizer alone (NPK) were significantly higher than those in the green manure treatments $(\mathrm{p}<0.05)$ (Figure 1). Furthermore, application rates of chemical fertilizer in the green manure treatments had significant effects on the abundance of nirS denitrifiers rather than that of nirK denitrifiers. Another interesting finding was that the abundance of nirK denitrifiers was significantly higher than that of nirS denitrifiers in all fertilization treatments, which was consistent with the result in a paddy soil by Chen et al (2010). Previous researchers reported that only one copy of nirK gene is observed in bacteria, whereas up to three $n i r S$ copies can be found in some bacterial strains (Jones et al., 2008). Therefore, in this study, the abundance of nirK denitrifiers would be even higher than that of nirS denitrifiers. However, higher abundance of nirS denitrifiers than that of nirK denitrifiers was observed in wheat-soybean rotation soils (Sun et al., 2015), in alkaline wheat soils (Yang et al., 2017) and in soybean-maize rotation soils (Yin et al., 2015). Paddy soil seems to possess a higher ratio of nirK/nirS, but it is not yet known how this might be related to the cultivation practice. Soil properties affected the abundance of nirS denitrifiers (Table 2). Soil pH was significantly positively correlated with $\operatorname{nir} S$ gene abundance $\left(\mathrm{r}^{2}=0.580, \mathrm{p}=0.023\right)$, which was demonstrated previously (Hallin et al., 2009; Yang et al., 2017). However, soil properties had less effect on the abundance of nirK denitrifiers.

It was previously reported that the composition and diversity of the denitrifying bacteria were affected by fertilization regimes (Chen et al., 2010; Yin et al., 2015; Yang et al., 2017). In our study, a notable discovery was that the community composition and diversity of $\operatorname{nirK}$ and $\operatorname{nir} S$ denitrifiers responded differentially to the fertilization regimes. The principal coordinate analysis revealed that community structure of nirK denitrifiers clearly changed between CK, chemical fertilizer and green manure treatments (i.e., MF80, MF60 and MF40) (Figure 3a), suggesting significant effect of green manure addition on nirK denitrifiers and weaker influence of application rates of chemical fertilizer. The relatively small effect of fertilization regimes on the community structure of nirS denitrifiers was observed (Figure 3b). These findings demonstrate the differences between nirK and nirS denitrifiers in response to fertilization regimes and suggest that habitat selective forces as a result of the application of fertilizer are more important than the nutrient content (Yin et al., 2015). Previous researchers have observed that fertilization regimes influenced the community of nirK denitrifiers but not nirS denitrifiers (Wolsing and Priemé, 2004; Chen et al., 2010). Although nirK and nirS genes are functionally equivalent, they mostly belong to different bacterial strains (Zumft, 1997) and show different responses to environmental variations. The distinct behaviors of nirK and nirS denitrifiers may be explained by the niche differentiation between them (Enwall et al., 2010). It is tempting to explain the maintenance of two types of nitrite reductases over bacterial evolution by niche differentiation, which can provide insurance against competitive exclusion (Hallin et al., 2009).

Based on the Miseq sequencing analysis of nirK gene, the identified dominant genera among the different treatments were affiliated to Bradyrhizobium, Mesorhizobium, and Nitrosospira which belonged to Rhizobiales and Nitrosomonadales, respectively. Chen et al. (2010) and Tang et al. (2016) also reported that nirK denitrifiers were mostly related to Rhizobiales. Different fertilization regimes resulted in obvious variations in the abundances of nirK denitrifiers in the different treatments. In comparison with NPK treatment, green manure treatments resulted in a decrease in the relative abundance of Rhizobiales and an increase in Nitrosomonadales (Figure 2a). These results demonstrated that the community structure of nirK denitrifiers responded to the addition of green manure. The dominance of nirK denitrifiers like Rhizobiales and Nitrosomonadales in paddy soil might indicate that they play an important role in denitrification. Furthermore, there were obvious differences in the occurrence of nirK denitrifiers genera among the fertilization treatments. The relative abundances of Nitrosospira were higher in the green manure treatments than that in the CK and NPK treatment, and unclassified Bradyrhizobiaceae exhibited contrast trend. In contrast, nirS denitrifiers were relatively stable against fertilization because the relative abundance of nirS denitrifier at the order or genera levels were similar in all five treatments without a significant variation (Figures $2 \mathrm{c}$ and $2 \mathrm{~d}$ ). The majority of nir $S$ denitrifiers were affiliated to the unclassified bacteria. In soils, nir $S$ denitrifiers were not well amplified due to primer specificity problems (Katsuyama et al., 2008). A small proportion of the genera like Azospira and Bradyrhizobium were identified by Miseq sequencing and there were no significant differences in the relative abundance of $n i r S$ genera. 
The RDA analysis suggested that PDA significantly affected the community structure of nirK denitrifiers but not nirS denitrifiers. This might imply that PDA explained some of the variability in nirK composition. For nirK community, pH had a strong impact on the community composition among soils with different fertilization regimes and it was previously reported that soil $\mathrm{pH}$ was a dominant factor in regulating the microbial community composition (Enwall et al., 2005; Fierer and Jackson, 2006). The soil OM content was also a predominant factor influencing nirK denitrifiers. The transformation of total organic matter can supply nutrients and energy which could stimulate the growth of soil microbes including $n i r K$ denitrifiers (Alden et al., 2001), and moreover, organic C is also an important factor influencing denitrifiers since it acts as an electron donor.

\section{CONCLUSIONS}

Our study showed that the incorporation of green manure and reduced chemical fertilizer were beneficial to maintain soil $\mathrm{N}$ contents. The abundances of nirK and nirS denitrifiers in the soil amended with chemical fertilizer alone were significantly higher than those in the treatments of the combination of green manure and reduced chemical fertilizer. The application of green manure and reduced chemical fertilizer had a strong impact on the community structures of nirK denitrifiers. The potential denitrifying activity (PDA) had strong impact on the abundance and community structure of nirK denitrifiers. The results improve our understanding of nir $K$ and nirS denitrifiers involved in the paddy soils amended with green manure and reduced chemical fertilizer.

\section{ACKNOWLEDGEMENTS}

This work was financially supported by the National Natural Science Foundation of China (41501269); Natural Science Foundation of Fujian Province (2017J01057); the Science and Technology Innovative Team Program of Fujian Academy of Agricultural Sciences (STIT2017-3-11); Youth Talent Program of Fujian Academy of Agricultural Sciences (YC2015-1); and the National Green Manure Industry System of China [grant number CARS-22-G-01].

\section{REFERENCES}

Alden, L., Demoling, F., and Baath, E. 2001. Rapid method of determining factors limiting bacterial growth in soil. Applied \& Environmental Microbiology 67(4):1830-1838. doi:10.1128/aem.67.4.1830-1838.2001.

Alfaro, M., Dube, F., and Zagal, E. 2018. Soil quality indicators in an Andisol under different tree covers in disturbed Nothofagus forests. Chilean Journal of Agricultural Research 78:106-116. doi:10.4067/S0718-58392018000100106

Braker, G., Zhou, J.Z., Wu, L.Y., Devol, A.H., and Tiedje, J.M. 2000. Nitrite reductase genes (nirK and nirS), as functional markers to investigate diversity of denitrifying bacteria in Pacific northwest marine sediment communities. Applied and Environmental Microbiology 66(5):2096-2104. doi:10.1128/AEM.66.5.2096-2104.2000.

Canfield, D.E., Glazer, A.N., and Falkowski, P.G. 2010. The evolution and future of earth's nitrogen cycle. Science 330:192196. doi:10.1126/science.1186120.

Chen, Z., Liu, J.B., Wu, M.N., Xie, X.L., Wu, J.S., and Wei, W.X. 2012. Differential response of denitrifying communities to fertilization regime in paddy soil. Microbial Ecology 63(2):446-459. doi:10.1007/s00248-011-9909-5.

Chen, Z., Luo, X.Q., Hu, R.G., Wu, M.N., Wu, J.S., and Wei, W.X. 2010. Impact of long-term fertilization on the composition of denitrifier communities based on nitrite reductase analyses in a paddy soil. Microbial Ecology 60(8):850-861. doi:10.1007/s00248-010-9700-z.

Cruz, A.F., Hamel, C., Hanson, K., Selles, F., and Zentner, R.P. 2009. Thirty-seven years of soil nitrogen and phosphorus fertility management shapes the structure and function of the soil microbial community in a Brown Chernozem. Plant and Soil 315(1-2):173-184. doi:10.1007/s11104-008-9742-x.

Cui, P.Y., Fan, F.L., and Yin, C., Song, A.L., Huang, P.R., Tang, Y.J., et al. 2016. Long-term organic and inorganic fertilization alters temperature sensitivity of $\mathrm{N}_{2} \mathrm{O}$ emissions and associated microbes. Soil Biology and Biochemistry 93:131-141. doi:10.1016/j.soilbio.2015.11.005.

Enwall, K., Philippot, L., and Hallin, S. 2005. Activity and composition of the denitrifying bacterial community respond differently to long-term fertilization. Applied \& Environmental Microbiology 71(12):8335-8343. doi:10.1128/AEM.71.12.8335-8343.2005. 
Enwall, K., Throbäck, I.N., Stenberg, M., Söderström, M., and Hallin, S. 2010. Soil resources influence spatial patterns of denitrifying communities at scales compatible with land management. Applied and Environmental Microbiology 76(7):22432250. doi:10.1128/AEM.02197-09.

FAO. 2003. Selected indicators of food and agriculture development in Asia-Pacific region 1992-2002. RAP Publication 2003/10. p. 23-24. FAO, Regional Office for Asia and the Pacific (RAP), Bangkok, Thailand.

Fierer, N., and Jackson, R.B. 2006. The diversity and biogeography of soil bacterial communities. Proceedings of the National Academy of Sciences of the United States of America 103(3):626-631. doi:10.1073/pnas.0507535103.

Hallin, S., Jones, C.M., Schloter, M., and Philippot, L. 2009. Relationship between N-cycling communities and ecosystem functioning in a 50-year-old fertilization experiment. The ISME Journal 3(5):597-605. doi:10.1038/ismej.2008.128.

Hallin, S., and Lindgren, P. E. 1999. PCR detection of genes encoding nitrite reductase in denitrifying bacteria. Applied and Environmental Microbiology 65(4):1652-1657. doi:10.2478/v10006-011-0029-7.

Hayatsu, M., Tago, K., and Saito, M. 2008. Various players in the nitrogen cycle: diversity and functions of the microorganisms involved in nitrification and denitrification. Soil Science and Plant Nutrition 54(1):33-45. doi:10.1111/j.1747-0765.2007.00195.x.

Huang, Y.F., Ye, Y.L., and Yang, S.Q. 2009. Feasibility of $\mathrm{NO}_{3}-\mathrm{N}$ determination by dual wavelength spectrophotometric method (In Chinese). Chinese Agricultural Science Bulletin 25(2):43-45.

Jones, C.M., and Hallin, S. 2010. Ecological and evolutionary factors underlying global and local assembly of denitrifier communities. The ISME Journal 4(5):633-641. doi:10.1038/ismej.2009.152.

Jones, C.M., Stres, B., Rosenquist, M., and Hallin, S. 2008. Phylogenetic analysis of nitrite, nitric oxide, and nitrous oxide respiratory enzymes reveal a complex evolutionary history for denitrification. Molecular Biology \& Evolution 25(9):19551966. doi:10.1093/molbev/msn146.

Katsuyama, C., Kondo, N., Suwa, Y., Yamagishi, T., Itoh, M., Ohte, N., et al. 2008. Denitrification activity and relevant bacteria revealed by nitrite reductase gene fragments in soil of temperate mixed forest. Microbes \& Environments 23(4):337-345. doi:10.1264/jsme2.me08541e.

Lashof, D.A., and Ahuja, D.R. 1990. Relative contributions of greenhouse gas emissions to global warming. Nature 344(6266):529-531. doi:10.1038/344529a0.

Levy-Booth, D.J., Prescott, C.E., and Grayston, S.J. 2014. Microbial functional genes involved in nitrogen fixation, nitrification and denitrification in forest ecosystems. Soil Biology and Biochemistry 75:11-25. doi:10.1016/j.soilbio.2014.03.021.

Lu, R.K. 2000. Analysis methods for soil agricultural chemistry. China Agricultural Science and Technology Press, Beijing, China.

Macguidwin, A.E., Knuteson, D.L. Connell, T., Bland, W.L., and Bartelt, K.D. 2012. Manipulating inoculum densities of Verticillium dahliae and Pratylenchus penetrans with green manure amendments and solarization influence potato yield. Phytopathology 102:519-527. doi:10.1094/PHYTO-07-11-0197.

Morales, S.E., Cosart, T., and Holben, W.E. 2010. Bacterial gene abundances as indicators of greenhouse gas emission in soils. The ISME Journal 4(6):799-808. doi:10.1038/ismej.2010.8.

Pell, M., Stenberg, B., Stenström, J., and Torstensson, L. 1996. Potential denitrification activity assay in soil-With or without chloramphenicol? Soil Biology \& Biochemistry 28(3):393-398. doi:10.1016/0038-0717(95)00149-2.

Ravishankara, A.R., Daniel, J.S., and Portmann, R.W. 2009. Nitrous oxide $\left(\mathrm{N}_{2} \mathrm{O}\right)$ : the dominant ozone-depleting substance emitted in the 21st century. Science 326(5949):123-125. doi:10.1126/science.1176985.

Savci, S. 2012. An agricultural pollutant: chemical fertilizer. International Journal of Environmental Science and Development 3(1):77-79. doi:10.7763/IJESD.2012.V3.191.

Sun, R.B., Guo, X.S., Wang, D.Z., and Chu, H.Y. 2015. Effects of long-term application of chemical and organic fertilizers on the abundance of microbial communities involved in the nitrogen cycle. Applied Soil Ecology 95:171-178. doi:10.1016/j.apsoil.2015.06.010.

Tang, Y.Q., Zhang, X.Y., Li, D.D., Wang, H.M., Chen, F.S., Fu, X.L., et al. 2016. Impacts of nitrogen and phosphorus additions on the abundance and community structure of ammonia oxidizers and denitrifying bacteria in Chinese fir plantations. Soil Biology and Biochemistry 103:284-293. doi:10.1016/j.soilbio.2016.09.001.

Throbäck, I.N., Enwall, K., Jarvis, A., and Hallin, S. 2004. Reassessing PCR primers targeting nirS, nirK and nosZ genes for community surveys of denitrifying bacteria with DGGE. FEMS Microbiology Ecology 49(3):401-417. doi:10.1016/j.femsec.2004.04.011.

Vitousek, P.M., Aber, J.D., Howarth, R.W., Likens, G.E., Matson, P.A., Schindler, D.W., et al. 1997. Human alteration of the global nitrogen cycle: sources and consequences. Ecological Applications 7(3):737-750. doi:10.1890/10510761(1997)007[0737:HAOTGN]2.0.CO;2.

Wolsing, M., and Priemé, A. 2004. Observation of high seasonal variation in community structure of denitrifying bacteria in arable soil receiving artificial fertilizer and cattle manure by determining T-RFLP of nir gene fragments. FEMS Microbiology Ecology 48(2):261-271. doi:10.1016/j.femsec.2004.02.002. 
Yan, X., Du, L., Shi, S., and Xing, G. 2000. Nitrous oxide emission from wetland rice soil as affected by the application of controlled-availability fertilizers and mid-season aeration. Biology and Fertility of Soils 32(1):60-66. doi:10.1007/ s003740000215.

Yan, T.F., Fields, M.W., Wu, L.Y., Zu, Y.G., Tiedje, J.M., and Zhou, J.Z. 2003. Molecular diversity and characterization of nitrite reductase gene fragments (nirK and nirS) from nitrate- and uranium-contaminated groundwater. Environmental Microbiology 5(1):13-24. doi:10.1046/j.1462-2920.2003.00393.x.

Yang, Y.D., Zhao, J., Jiang, Y., Hu, Y.G., Zhang, M.C., and Zeng, Z.H. 2017. Response of bacteria harboring nirS and nirK genes to different $\mathrm{N}$ fertilization rates in an alkaline northern Chinese soil. European Journal of Soil Biology 82:1-9. doi:10.1016/j. ejsobi.2017.05.006.

Yin, C., Fan, F.L., Song, A.L., Cui, P.Y., Li, T.Q., and Liang, Y.C. 2015. Denitrification potential under different fertilization regimes is closely coupled with changes in the denitrifying community in a black soil. Applied Microbiology \& Biotechnology 99(13):5719-5729. doi:10.1007/s00253-015-6461-0.

Zumft, W.G. 1997. Cell biology and molecular basis of denitrification. Microbiology and Molecular Biology Reviews 61(4):533-616. 